\title{
Dyadic Coping in Foster and Biological Parents and Its Relation to Child Psychopathology
}

\section{Longitudinal Results}

\author{
Ann-Katrin Job ${ }^{1}$, Denise Kerkhoff ${ }^{2}$, Fridtjof W. Nussbeck ${ }^{3}$, Kerstin Konrad ${ }^{4,5}$, \\ Nina Heinrichs ${ }^{6}$, and Arnold Lohaus ${ }^{2}$ \\ ${ }^{1}$ Department of Psychology, University of Braunschweig, Germany \\ ${ }^{2}$ Department of Psychology, Bielefeld University, Germany \\ ${ }^{3}$ Department of Psychology, University of Konstanz, Germany \\ ${ }^{4}$ Clinical Child Neuropsychology Section, University Hospital Aachen, Germany \\ ${ }^{5}$ JARA Brain Institute II, Juelich, Germany \\ ${ }^{6}$ Department of Psychology, University of Bremen, Germany
}

\begin{abstract}
This study investigated whether foster parents' reports of their dyadic coping competencies differ from biological parents, whether there are differences with regard to the temporal associations between maternal and paternal dyadic coping in the two samples, and whether parental dyadic coping competencies predict future mental health problems in children. A total of 94 foster children and 157 children living in their biological families, both samples aged 2-7 years, as well as their (foster) parents were assessed three times over a 12-month period. The mothers' and fathers' dyadic coping competencies were assessed using the Dyadic Coping Inventory (DCl). Child psychopathology was assessed using the Child Behavior Checklist (CBCL) and a standardized clinical interview (Kinder-DIPS), both mainly based on maternal report. Foster parents reported better dyadic coping competencies across the three assessments than did biological parents. There were no significant differences with regard to the temporal associations between mothers' and fathers' report over time between the two samples. Cross-lagged panel models yielded a high within person stability across the three assessments for both, mothers and fathers (actor effects), as well as some significant interpersonal effects primarily from paternal to maternal dyadic coping (partner effects). In contrast to the expectation, mothers' and fathers' dyadic coping did not predict child mental health problems at the third assessment. The results make an important contribution to the research on dyadic coping and on how child mental health problems affect parental dyadic coping competencies and vice versa.
\end{abstract}

Keywords: dyadic coping, child mental health problems, foster children, foster parents, child maltreatment

\section{Increased Risk of Mental Health Problems in Foster Children}

Children with a history of maltreatment and neglect have an increased risk of developing mental health problems. Burns et al. (2004) found $48 \%$ of maltreated children and youths to show clinically significant emotional or behavioral problems. According to Briggs-Gowan, Horwitz, Schwab-Stone, Leventhal, and Leaf (2000) child maltreatment increased the likelihood of meeting the criteria for any mental disorder by a factor of 2.9.

The placement of maltreated and neglected children in a foster family is one of the most common steps to protect affected children from further harm and to promote a healthy development. Studies on the mental health of foster children, however, still yield significantly increased prevalence rates of child emotional and behavior problems compared to children who are not living in out-of-home care. In a recent meta-analysis, Vasileva and Petermann (2018) found high prevalence rates of about 39\% for mental health problems, $43 \%$ for insecure attachment, and 39\% for developmental problems in foster children aged 7 years or younger. Another meta-analysis by Goemans, van Geel, and Vedder (2015) on the effect of placement in a foster family on child well-being yielded significant changes neither with regard to internalizing or externalizing behavior problems nor with regard to the adaptive functioning of foster children. In the United Kingdom, former foster children furthermore were found to have the poorest outcomes with regard to mental health problems, smoking, 
criminal conviction, and social support in adulthood compared to former adopted children and a normal reference group (Teyhan, Wijedasa, \& Macleod, 2018). Although there is some indication that adaptive functions may increase if children are adopted after experiencing early institutional care (e.g., emotion regulation abilities; Perry, Donzella, Parenteau, Desjardins, \& Gunnar, 2019), they remain worse than in never-institutionalized children. Early adversity may have fundamental impact on the development of a child across a number of domains including school functioning, self-regulation skills, or mental health.

Raising a foster child with a history of child maltreatment and neglect may thus be much more challenging for couples as parents than raising a biological child. As a consequence, it is of high importance to investigate potential risk factors and resources to derive starting points for prevention and to better support foster children and their families.

\section{Dyadic Coping and Its Relation to Children's Well-Being}

The parental relationship generally has an important impact on children's well-being (e.g., Amato, 2010; Cummings \& Davies, 2010). In particular, the way parents interact and communicate with each other as well as how they deal with conflicts seem to significantly affect their children (see Brock \& Kochanska, 2016; McCoy, Cummings, \& Davies, 2009; Zemp, Bodenmann, \& Cummings, 2016; Zemp, Merrilees, \& Bodenmann, 2014). Research findings indicate that children who experience chronic conflicts between parents have an increased risk to develop psychological and somatic disorders, a low self-esteem, adjustment problems as well as problems in school performance (see Cummings \& Davies, 2010; Zemp, Bodenmann, \& Cummings, 2016, for a review). It should, however, be noted that also the other direction is possible (i.e., children's problems may affect the parental relationship) which is outlined in more detail below.

According to Bodenmann (2000), the frequency and intensity of destructive conflicts and couple discord are significantly related to the partners' every day stresses. Stress thereby is defined as a subjectively experienced imbalance between the valuation of an external requirement (primary appraisal) and the available resources (secondary appraisal; Lazarus \& Folkman, 1984). With regard to couples coping with stress, the Transactional Stress Model proposes that individual stress usually not only affects one partner but spills over from the affected partner to the other (Bodenmann, Randall, \& Falconier, 2016). Dyadic stress can be defined as a stressor that affects both partners. This may occur because an individual stress experience is spilling over into the dyadic relationship or because both partners are confronted with a common stressor (e.g., jointly raising a child with emotional and/or behavior problems). Besides the partners' individual coping strategies, the couples' relationship and their common stress management of daily requirements are thus also of great importance for couples' long-term relationship satisfaction (Bodenmann, 2000, 2004; Zimet \& Jacob, 2001). In this context, the concept of dyadic coping (DC), which is defined as the way in which couples jointly cope with their everyday stress experiences (Bodenmann, 2000, 2004), has become more and more important during the last decades. DC may be conceptualized as a form of "dyadic stress management" (Traa, De Vries, Bodenmann, \& Den Oudsten, 2015, p. 85) in which - ideally - both members of a dyad support each other in reducing the experience of stress. Low DC competencies may therefore be a risk factor for relationship discord (e.g., Hilpert, Bodenmann, Nussbeck, \& Bradbury, 2013; Hilpert et al., 2016), for example, because one partner may not feel supported by the other in dealing with his or her stressful experiences.

With regard to the DC of parents, various studies have shown that a reciprocal support system of both partners is particularly important to master the parental role and the educational task of raising a child (e.g., Feinberg, 2002; Feinberg et al., 2016). Being a parent usually comes along with a redefinition of roles, a reorganization of daily routines, reduced time for being together as a couple, and a persistent increase in daily stress (e.g., Keizer \& Schenk, 2012). If the parents lack adequate coping competencies, child-related stress may spill over to the parental relationship, impair the parental communication, and lead to a reduced relationship satisfaction in couples (Mitnick, Heyman, \& Smith Slep, 2009; Zemp, Nussbeck, Cummings, \& Bodenmann, 2017). Low DC competencies may also be a risk factor for child maladjustment (e.g., Zemp, Bodenmann, Backes, et al., 2016), while high DC competencies are an important protective factor for child mental health (e.g., Cina \& Bodenmann, 2009; Zemp, Milek, et al., 2016).

In sum, DC is considered a couple-based competency that may strengthen parents as partners and therefore support them in responding more sensitively to challenging child behaviors as the couple can approach these challenges together, combining their strengths. This effect may only be observed in situations where couples are challenged in their role as parents (buffering effect), while it may not make a difference when couples are not challenged in their parenting role. Thus, the level of challenging behavior may be important in eliciting DC.

Although the parental dyad can be assumed to have a significant impact on foster children's development, there are to date hardly any studies on the association between the DC of foster parents or the parental intimate relationship in general and mental health problems of foster children. 


\section{Increased Child Problem Behaviors and Their Impact on Parental Dyadic Coping}

Parents of children with emotional and behavior problems usually report higher levels of intra- (parenting, intimate relationship, health) as well as extra- (socio-economic conditions, social support) family stress and have lower and more unfavorable coping strategies compared to parents of children without any behavior problems (Johnston \& Mash, 2001; Morgan, Robinson, \& Aldridge, 2002; Zemp, 2018; Zimet \& Jacob, 2001). Gabriel and Bodenmann (2006a) compared the level of every day stress and DC between parents of (1) healthy boys $(n=24)$, (2) boys with conduct problems only $(n=18)$, and (3) boys with attention deficit and conduct problems $(n=27)$, all aged 6-14 years. They found parents of the two groups with child behavior problems to report significantly higher levels of stress in their daily family life and less positive DC (higher negativity in mothers' report and less joint DC in fathers' report) compared to the parents in the healthy control group.

However, not all child difficulties seem to have a significant negative impact on the DC of parents. Obermüller (2012) found significantly higher parenting stress in mothers and fathers of a child with an intellectual disability compared to parents of a healthy child (total $n=158$, child's age: $\leq 20$ years), but found no significant differences with regard to the use of positive or negative DC strategies (assessed with the Dyadic Coping Inventory DCI; Bodenmann, 2008a). Another study by Gabriel, Zeender, and Bodenmann (2005) yielded significantly increased stress levels in parents of children with Down syndrome $(n=53)$ as well as in parents of children with externalizing behavior problems $(n=54)$ compared to parents of healthy children ( $n=43)$ (child's age: 6-14 years). However, while parents of a child with externalizing behavior problems also reported the most unfavorable DC competencies (also assessed with the DCI; Bodenmann, 2008a), parents of a child with Down syndrome reported the best DC competencies compared to the other two groups. The authors explained their findings by remarking that the Down syndrome, at the latest, had been diagnosed 6 months after the birth of the child. The initial shock as well as the individual disappointment and parental worries could have led to an increased DC (because of the shared suffering both parents may join forces to fight against the daily stresses). The question about the cause and the handling of externalizing child behavior problems (e.g., a pampering or inconsistent parenting style of one partner), in contrast, may divide parents (Zimet \& Jacob, 2001). In this context, the extent of child behavior problems also seems to play an important role. Although Gabriel and Bodenmann (2006b) found parents of a child with clinically relevant attention and conduct problems $(n=30)$ as well as parents of a child with only conduct problems $(n=19)$ to report significantly increased stress levels compared to parents of a healthy child $(n=34)$, only parents with a child with attention and conduct problems reported significantly lower DC competencies compared to the other two groups.

\section{The Other Influential Direction: Parental Dyadic Coping and Its Impact on Children's Behavior}

The association between child behavior problems and the parental relationship expressed, for example, in their DC competencies, however, should not be considered as unidirectional but bidirectional (e.g., Zemp, 2018). Zemp, Bodenmann, Backes, et al. (2016) examined parental DC as a predictor of child behavior in three cross-sectional studies with typically developing healthy children. As a result they found that parental DC was significantly associated with children's internalizing and externalizing behavior problems as well as prosocial behavior across informants and measures of DC (parent-report: $n=354$, $M=9.3$ years, range: $4-18$ years; child-report: $n=187$, $M=11.8$ years, range: $11-13$; behavior observation: $n=38$; $M=12.3$, range: $9-17$ years). The authors concluded that children experience fewer behavior problems and greater prosocial behavior in families where parents demonstrate greater DC competencies and vice versa. The partners' DC competencies thereby seem to be significantly related to parental conflicts about parenting, which in turn are significantly related to externalizing and internalizing child behavior problems (Gabriel \& Bodenmann, 2006c).

Because foster caregivers are often confronted with challenging child behavior, previous studies with a focus on foster families often investigated the level of parental stress in the daily family life (e.g., Chamberlain et al., 2006; Vanschoonlandt, Vanderfaeillie, Van Holen, De Maeyer, \& Robberechts, 2013). Russell (2014) reported data of a cross-sectional study on how fostering affects the parental dyad. She examined the associations between the foster parents' quality of marriage, emotional stress, as well as spousal support, and concluded that a favorable support system between foster parents and effective DC seem to be especially important for the mastery of everyday stresses in foster families. The generalization of findings from crosssectional studies is however limited. Moreover, the study neither investigated differences of the foster parental dyad compared to the general population, nor investigated the impact of the quality of the parental relationship on child outcomes. The aim of the present study was to provide the first results to fill this gap. 


\section{The Current Study}

This study explores DC as an important aspect of the intimate relationship of parents and its association with their child's mental health problems in a longitudinal study with foster families and compared the results to parents raising their biological child. The data come from the German GROW\&TREAT-project where we reassessed a sample of foster parents and their young foster children with a history of maltreatment and/or neglect and a sample of parents and their biological children without these negative experiences three times over a period of 1 year. The longitudinal design of the project not only allows for a cross-sectional comparison between the two samples but also to investigate the development of DC over time and its relation to child mental health problems.

In an earlier publication of data from the GROW\&TREAT-project, Lohaus et al. (2017) found that the foster children of the present sample show increased mental health problems associated with increased parental stress experiences. The increased stress experiences, in turn, could have a negative impact on the parental DC compared to families who only raise their biological children. On the other hand, foster parents deliberately and jointly decide to take care of a foster child. This may indicate that couples who decide to become foster parents have a better relationship functioning from the very start compared to couples from the general population and may therefore be better able to jointly cope with increased levels of stress. Foster parents are furthermore usually aware of the increased challenges associated with raising a foster child (e.g., because they may have been informed about the increased risk of foster children to develop mental health problems by the youth welfare offices). Biological parents, in contrast, are more often surprised by significant child emotional and behavior problems and do not always know how to successfully cope with this challenge (Zimet \& Jacob, 2001). As a consequence, it is possible to expect increased as well as decreased DC competencies in foster parents (e.g., because of negative effects of the children's behavioral problems on DC in foster parents).

\section{Hypotheses}

Based on these considerations, an important aim of this study is to investigate whether foster parents' report of their overall DC competencies and, in particular, their joint DC significantly differ from biological parents at the time of the baseline assessment and also longitudinally (Hypothesis 1). Because this is the first study to investigate this difference, we did not make specific predictions regarding the direction of the difference. In addition to the mean differences addressed in Hypothesis 1, we also investigated whether there are significant differences regarding the temporal associations between maternal and paternal DC both within and across different time points in foster families in comparison to biological families. Because foster parents usually jointly decide to take care of a foster child and thus to jointly meet the potentially emerging challenges, we assumed foster parents to show more concordant DC efforts and to have a stronger mutual influence with regard to their DC compared to biological parents over time (Hypothesis 2a). We additionally analyzed if this DC structure is altered if we control for the influence of child mental health problems (Hypothesis 2b). Finally, we explored whether parental DC significantly predicted child mental health problems at the third assessment in both samples. Based on the earlier findings, we hypothesized that both, foster and biological children of (foster) parents with better DC skills show less mental health problems and vice versa (Hypothesis 3).

\section{Method}

The GROW\&TREAT project included a longitudinal developmental outcome study with three assessment points (each in intervals of about 6 months) and an intervention study. Between 2013 and 2017, it was carried out in the regions of the three German cities Aachen, Bielefeld, and Braunschweig.

The foster families were mainly recruited through the regional youth welfare offices at the three sites and occasionally through Internet platforms. Foster children's age should be between 2 and 7 years, because in Germany children of these age groups are typically placed in foster families rather than foster institutions. Moreover, they should have been placed in the foster family because of child maltreatment and/or neglect in their biological family, and should not have lived in their current foster family for longer than 24 months. The latter inclusion criterion was used, because the focus should be set on a developing family system with a new foster child and not an already stabilized family system. We furthermore recruited a comparison group of children of the same age, who lived with their biological parents and had no known experiences of maltreatment or neglect. The comparison group was recruited in the same regions as the foster families via postings or parents' evenings in nursery and elementary schools. To participate in the study, those who were holding child custody (biological parent[s], foster parent[s]), or legal guardian) had to give their written informed consent for a family's participation in the project.

Foster and biological mothers as well as fathers participated in the study. The assessments included several parent 
report questionnaires, a family background interview, a structured clinical interview as well as other assessments that are not considered in the following analyses. An overview on all data assessed within the GROW\&TREATproject can be found on our project website http://www. grow-and-treat.de (currently password-protected because of a new data protection regulation; the password can be requested from the corresponding author). All procedures and assessments were approved from an independent ethics committee. The foster as well as the biological families received $30 €$ as incentive for participation at each assessment and a final payment of $30 €$, if they had participated at all three assessments.

\section{Sample}

A total of 94 foster children and 157 children living in their biological families participated in the project. Of these, about $49 \%(n=46)$ of the foster children and about $52 \%$ ( $n=82$ ) of the biological children were female. This difference turned out to be nonsignificant. The mean age of the foster children was 3.8 years $(S D=1.6)$ and of the biological children 4.4 years $(S D=1.5)$. The parents' mean age was 41.3 years $(S D=6.8)$ for foster mothers, 35.5 years $(S D=$ $5.2)$ for biological mothers, 44.8 years $(S D=6.8)$ for foster fathers, and 38.5 years $(S D=5.8)$ for biological fathers. All three age differences between the two samples turned out to be significant (children: $t=3.22, d f=249, p<.01$; mothers: $t=-7.11, d f=157.8, p<.001$; fathers: $t=$ -7.66, $d f=239, p<.001)$. Based on Pearson correlations, however, neither children's age, nor mothers' or fathers' age proved to be significantly related to the parental DC scores. With regard to their family status, $89 \%$ of the foster parents and $81 \%$ of the biological parents reported being married. The other parents reported being unmarried but in a long-term relationship (foster: $4 \%$; biological: $11 \%$ ) or being single (foster: 6\%; biological: $6 \%$ ), which means that there are no DC data in these cases. Cases with no DC data were not included in the analyses focusing on DC. The average length of the parental relationship was 15.3 years $(S D=8.4)$ for the foster and 11.9 years $(S D=5.3)$ for the biological parents. While the difference in family status between the two samples turned out to be nonsignificant, the difference in relationship duration was significant $(t=$ -3.39, $d f=126.7, p<.01)$. Relationship duration was, however, proved to be unrelated to the parental DC scores. Of the foster families, $9 \%$ had a low socio-economic status (SES), 55\% belonged to the middle class, and $36 \%$ had a high SES. For the biological families, the distribution of the SES was as follows: low: 9\%, middle: 47\%, high: $44 \%$. There was no significant difference between the distributions among the two samples $\left(\chi^{2}=1.6 ; d f=2 ; p=.457\right)$. With regard to siblings, $45 \%$ of the foster parents reported to have 1-6 biological children, leading to an average number of biological children in the foster families of $M=1.1$ $(S D=1.3)$. In the biological families, $77 \%$ of parents reported to have more than one biological child (range: $1-5)$, leading to an average number of biological children in these families of $M=2.1(S D=0.9)$. This difference turned out to be significant $(t=6.3 ; d f=141.1 ; p \leq .001)$. Forty-six percent of the foster families, however, reported to have already taken care for more than one foster child $(M=2.4 ; S D=2.8)$. At the time of the first assessment a total of $M=2.4(S D=1.6)$ children lived in the foster families (including biological and foster children as well as the index child) and a total of $M=2.0(S D=0.8)$ children in the biological families. This difference also turned out to be significant $(t=-2.2 ; d f=118.2 ; p=.030)$. However again, neither the number of biological children, nor the number of foster children or the number of (foster) children living in the (foster) families at the time of the first assessment was significantly related to the parental DC scores.

Before becoming foster parents, couples usually receive some kind of preparation and are later usually offered a lot of support for their family and their foster child. With regard to parenting trainings, $21 \%$ of the biological parents and $34 \%$ of the foster parents reported to have taken part in any kind of parent training before the first assessment of the project. This difference turned out to be significant $\left(\chi^{2}=5.2 ; d f=1 ; p=.023\right)$. Of the biological parents who participated in any kind of parent training, 33\% participated in the German program Starke Eltern - Starke Kinder (Strong Parents - Strong Children), 9\% in any kind of Triple P intervention, and $58 \%$ in any other intervention (parenting training, lectures, etc.). Among the foster families, the parenting interventions were a lot more diverse, only 13\% participated in the Starke Eltern - Starke Kinder program, 3\% in Starke Eltern - Starke Kinder and a Triple P intervention, and the other $84 \%$ in any other intervention (parenting training, lectures, etc.). Based on the results of two-tailed $t$-tests, the DC scores of foster and biological parents who participated in any kind of parenting intervention, however, did not significantly differ from the DC scores of parents who did not make use of any parenting intervention.

After the baseline assessment, about half of the foster families were randomly selected and offered to participate in a parenting group training between the first and second assessment with five weekly sessions, two telephone consultations, and a final meeting back in the group. The applied parenting training was a modified Triple $\mathrm{P}$ intervention adapted to the specific needs of foster parents (Taking Care Triple P; Chandler \& Sanders, 2013). Analyses of variance were calculated for the foster families with group (intervention versus no intervention) as between-subject and sex of the partner (male vs. female) as well as time of assessment as within-subject factors. The analyses yielded no significant 
interactions of the DC scores as dependent variables with the factor intervention in the foster parents group. The patterns of the DCI scores are similar and independent of the intervention. As a consequence, this factor was not included in the following analyses.

Complete longitudinal DC data was available for 187 mothers (69 foster and 118 biological mothers) and 178 fathers (68 foster and 110 biological fathers). With regard to the parental dyads complete datasets were available for 175 mothers and fathers of the same family (68 foster and 107 biological families). There were no significant differences between the initial assessments of the parents who provided complete data on their DC throughout all three assessments and those who dropped out from the study or provided incomplete data.

At the baseline assessment, the foster children lived on average 17.6 months $(S D=8.8)$ in their foster families. Most of the foster children (72\%) were from German born parents and $21 \%$ had a migration background (with a wide range of countries of origin). If the foster or biological families had more than one child in the target age, they were asked to select one of the children as target child (based on a random choice). In few cases ( $n=7$ foster and $n=8$ biological families), however, the assessments were completed for more than one child to avoid dropout. After the research project was completed, it was decided to leave these children in the sample to avoid too small sample sizes for the longitudinal analyses.

\section{Assessments}

DC of the (foster) parents was assessed using the Dyadic Coping Inventory (DCI; Bodenmann, 2008a). The DCI aims at measuring how couples cope with common everyday stressors. Based on a set of 37 items, participants are asked to assess their stress communication and DC using 5 -point response scales ranging from 1 (= very rarely) to 5 (= very often). Examples of items are "I ask my partner to do things for me when I have too much to do" and "We try to cope with the problem together and search for ascertained solutions". The focus of this study is related to the DC total score, which is based on 35 items of the DCI (after reversing the negative DC items). In addition, the subscale of joint dyadic coping (joint DC) was used in this study, which is related to joint coping processes in which both partners engage together in coping with common stressors (based on items 31-35). Two additional items are available to evaluate the overall satisfaction with the DC; however, these items are not used in this study. The following sections are thus based on the DC total score and the subscale related to the joint DC of partners. For both scores the mean rating across the included items was used for the analyses (allowing for 20\% missing values on each scale). The mean score was preferred here, because the use of the sum score would have increased the amount of missing values for the DC scores. At baseline, the internal consistencies of the DC total mean score were $\alpha=.94$ for foster mothers, $\alpha=.92$ for biological mothers, $\alpha=.93$ for foster fathers, and $\alpha=.90$ for biological fathers. For the subscale related to joint DC the internal consistencies were $\alpha=.70$ for foster mothers, $\alpha=.78$ for biological mothers, $\alpha=.73$ for foster fathers, and $\alpha=.77$ for biological fathers.

Child mental health problems were assessed in two ways: dimensionally with the German versions of the Child Behavior Checklist (CBCL) and categorically with a structured clinical interview for child mental disorders (Diagnostic Interview of Mental Disorders in Childhood and Adolescents, Kinder-DIPS).

The CBCL 1.5-5 (Achenbach \& Rescorla, 2000) was used in an age range from 2 to 4 years, while the CBCL 4-18 (Achenbach, 1991) was used, if the children were 5 years or older. The CBCL $1.5-5$ consists of 100 items dealing with child emotional and behavioral problems, the CBCL 4-18 of 118 items. In both questionnaires, parents rate their children using a three step response format $(0=$ not true $; 1$ = somewhat or sometimes true; 2 = very true or often true). The externalizing scale assesses primarily conduct problems, for example, "Disobedient" (CBCL 1.5-5) and "Lies" (CBCL 4-18), the internalizing scale primarily withdrawal, depression, and anxiety, for example, "Looks unhappy" (CBCL 1.5-5) and "Cries" (CBCL 4-18). In all cases, $t$-values were calculated for the raw values and used for the analyses reported below. The CBCL reports were typically only provided by the (foster) mothers (in $81 \%$ of all cases), while $8 \%$ of the CBCL assessments were completed by (foster) fathers, and $11 \%$ jointly by both (foster) parents. At the initial assessment, the internal consistencies in the foster children sample were $\alpha=.92$ (CBCL 1.5-5) and $\alpha=.86$ (CBCL 4-18) for internalizing and $\alpha=.89$ (CBCL 1.5-5) and $\alpha=.91$ (CBCL 4-18) for externalizing behavior problems. In the comparison group they were $\alpha=.82$ (CBCL 1.5-5) and $\alpha=.74$ (CBCL 4-18) for internalizing and $\alpha=.88$ (CBCL 1.5-5) and $\alpha=.86$ (CBCL 4-18) for externalizing behavior problems. The correlation between the externalizing and internalizing scale $t$-values was $r=.67$, $p<.001$.

For the categorical assessment we used the Kinder-DIPS (Unnewehr, Adornetto, Suppiger, Margraf, \& Schneider, 2009), which is an extended and modified version of the Anxiety Disorders Interview Schedule-Revised (ADIS-R; DiNardo \& Barlow, 1988). The Kinder-DIPS covers the most frequent mental disorders in children and youth and is conducted by trained interviewers. It shows a good validity (Schneider, Suppiger, Adornetto, \& Unnewehr, 2009) 
and inter-rater reliability (Neuschwander, In-Albon, Adornetto, Roth, \& Schneider, 2013). Within the GROW\&TREAT project, the parent version of the Kinder-DIPS was applied to assess current child mental disorders according to the ICD-10. Examples of introductory questions are, for example, "Is your child very aggressive, violent against other persons, involved in brawls, does it steal or often run away?" for conduct disorders and "Are there things your child is afraid of (e.g., certain animals or darkness)" for specific phobias. The prevalence rates in the total sample were $21 \%$ at the first and second assessment and $18 \%$ at the third assessment. The average severity ratings of the primary disorder (range: $4-8)$ were $M=4.8(S D=0.9)$ at the first, $M=4.7(S D=0.8)$ at the second, and $M=4.8$ $(S D=0.6)$ at the third assessment. With regard to comorbidity, $50 \%$ of the children with a diagnosis met the criteria for more than on ICD-10 mental disorder at the first assessment, $25 \%$ at the second assessment, and $28 \%$ at the third assessment. Because the comorbidity rates were even smaller than the prevalence rates, in the following, we only analysed whether the presence of at least one current child mental disorder (yes/no) showed a significant relation to parental DC across the three assessments. The DC assessments were typically provided by both parents, while the CBCL was completed only by one parent (in most cases the mother). The interviews (Kinder-DIPS) were conducted by trained interviewers (in most cases with only one parent, typically the mother).

\section{Statistical Analyses}

Expected mean differences regarding the DC total mean score and the joint DC between foster and biological parents (Hypothesis 1) were tested each using a $2 \times 2 \times$ 3 univariate within-subject mixed analysis of variance with type of family as between and sex of the partner as well as time of assessment as within subjects factors. Because Lohaus et al. (2017) found significant differences between the foster and biological children of the present sample with regard to their mental health scores, in a second step, the internalizing and externalizing problem behavior scores (CBCL) at $\mathrm{t} 1-\mathrm{t} 3$ were included in the analyses as covariates to test whether the differences in the DC scores may be explained by the mental health differences between the foster and biological children.

Hypothesis 2 focused on the temporal relationships between maternal and paternal DC across the three assessments. Cross-lagged panel analyses were estimated (1) to identify the temporal relation and (2) to identify potential differential trajectories over time between the foster and biological parents via model comparisons (Hypothesis 2a). As an additional step, we analyzed whether the relationships found in Hypothesis $2 \mathrm{a}$ are changed by including the child mental health indicators in the analyses (Hypothesis 2b). Therefore, children's problem behavior scores (CBCL) and, after that, the presence of an ICD-10 child mental disorder (Kinder-DIPS) were included as predictors in the cross-lagged panel models. Estimates of the resulting cross-lagged panel models were then compared via model comparisons.

In the last step, we analyzed whether mothers' and fathers' total DC or joint DC significantly predicted child mental health problems at $\mathrm{t} 3$ (Hypothesis 3). For the prediction of externalizing and internalizing child behavior problems (CBCL) hierarchical multiple regression analyses were conducted. With regard to the presence of an ICD-10 child mental disorder (Kinder-DIPS) we carried out stepwise logistic regressions.

All analyses were based on two-tailed significance testing. Analyses were conducted using IBM SPSS Statistics 25 (IBM Corp., 2018) and Mplus 8 (Muthén \& Muthén, 2017).

\section{Results}

\section{Descriptives}

The means and standard deviations of the DC total mean score and the subscale of joint DC for both, mothers and fathers of the two samples are shown in Table 1 (tables with means and standard deviations of all DCI subscales are provided in Electronic Supplementary Material, ESM 1 - Tables E1 and E2).

\section{Dyadic Coping Differences Between Foster and Biological Parents (Hypothesis 1)}

With regard to the DC total mean score, a univariate analysis of variance with family type (foster vs. biological parents) as between-subject and male versus female partner as well as time of assessment (t1, t2, t3) as within-subject factors provided a significant difference between the two samples (foster vs. biological parents; $F(1,173)=7.31, p=.008, \eta^{2}=$ .041). As shown in Figure 1, the score is increased in the foster sample in comparison to the biological sample (indicating better DC in foster parents). There were no additional statistically significant effects for time of assessment and sex of the partner as well as no interaction.

Regarding the joint DC mean score there was again a significant group effect, $F(1,166)=9.22, p=.003, \eta^{2}=.053$, indicating increased joint DC in foster parents compared to the biological parents (see Figure 2). In addition, the analysis yielded a significant interaction between family type (foster vs. biological family) and time of assessment, 
Table 1. Means $(M)$ and standard deviations (SD) of the foster and biological mothers' and fathers' $D C l$ total mean Score and the DCI subscale "joint dyadic coping" across the three assessments

\begin{tabular}{|c|c|c|c|c|c|c|c|c|c|c|c|c|}
\hline & \multicolumn{6}{|c|}{ Foster families } & \multicolumn{6}{|c|}{ Biological families } \\
\hline & \multicolumn{2}{|r|}{$\mathrm{T} 1$} & \multicolumn{2}{|r|}{$\mathrm{T} 2$} & \multicolumn{2}{|r|}{ T3 } & \multicolumn{2}{|r|}{$\mathrm{T} 1$} & \multicolumn{2}{|r|}{$\mathrm{T} 2$} & \multicolumn{2}{|r|}{ T3 } \\
\hline & $n$ & $M(S D)$ & $n$ & $M(S D)$ & $n$ & $M(S D)$ & $n$ & $M(S D)$ & $n$ & $M(S D)$ & $n$ & $M(S D)$ \\
\hline \multicolumn{13}{|c|}{ DCl total score } \\
\hline Mothers & 85 & $3.77(0.50)$ & 75 & $3.82(0.47)$ & 73 & $3.80(0.51)$ & 136 & $3.62(0.49)$ & 130 & $3.65(0.48)$ & 127 & $3.66(0.45)$ \\
\hline Fathers & 83 & $3.76(0.45)$ & 74 & $3.79(0.43)$ & 73 & $3.77(0.40)$ & 130 & $3.66(0.39)$ & 122 & $3.62(0.41)$ & 120 & $3.58(0.43)$ \\
\hline \multicolumn{13}{|c|}{$\mathrm{DCl}$ joint dyadic coping } \\
\hline Mothers & 82 & $3.43(0.63)$ & 73 & $3.45(0.73)$ & 70 & $3.48(0.72)$ & 133 & $3.14(0.71)$ & 130 & $3.24(0.76)$ & 127 & $3.24(0.72)$ \\
\hline Fathers & 82 & $3.39(0.62)$ & 71 & $3.56(0.66)$ & 70 & $3.53(0.67)$ & 130 & $3.25(0.61)$ & 122 & $3.20(0.64)$ & 120 & $3.13(0.61)$ \\
\hline
\end{tabular}

Note. $\mathrm{DCl}=$ Dyadic Coping Inventory (Bodenmann, 2008a); DCl mean score range $=1-5 ; n=$ cases with complete DCl data per assessment.

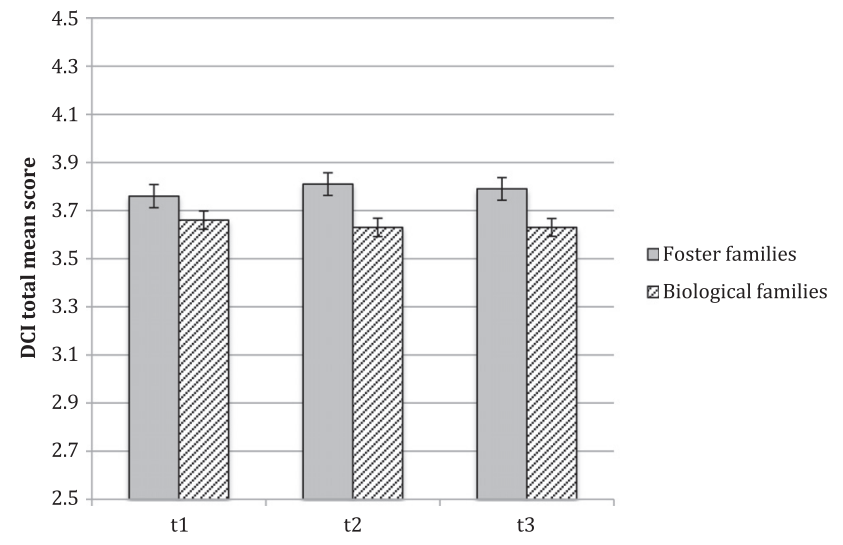

Figure 1. Changes in the total dyadic coping mean score for foster versus biological families across the three assessments (the error bars show the standard errors of the mean).

$F(2,332)=3.50, p=.033, \eta^{2}=.021$, indicating an increasing difference between the two samples to the advantage of the foster families over time (see Figure 2). There were no additional statistically significant effects. A table with the complete results of both analyses of variance (regarding the DC total mean score and the joint DC mean score) is provided in ESM 1 - Table E3.

By including the internalizing and externalizing problem behavior scores (CBCL) at $\mathrm{t} 1-\mathrm{t} 3$ in the analyses as covariates, the analyses for the DC total mean score again yielded a significant difference between the two samples in favor of the foster parents, $F(1,159)=8.06, p=.005, \eta^{2}=.048$, and no additional effects. Regarding the joint DC mean score, the significant group effect, $F(1,152)=6.59, p=.011, \eta^{2}=$ .042 , was also maintained as well as the significant interaction between family type and time of assessment, $F(2,304)=4.45, p=.012, \eta^{2}=.028$.

To summarize, the analyses of variance provide evidence for sample differences, which are consistently showing increased DC competencies in the foster compared to the biological parents across the three assessments.

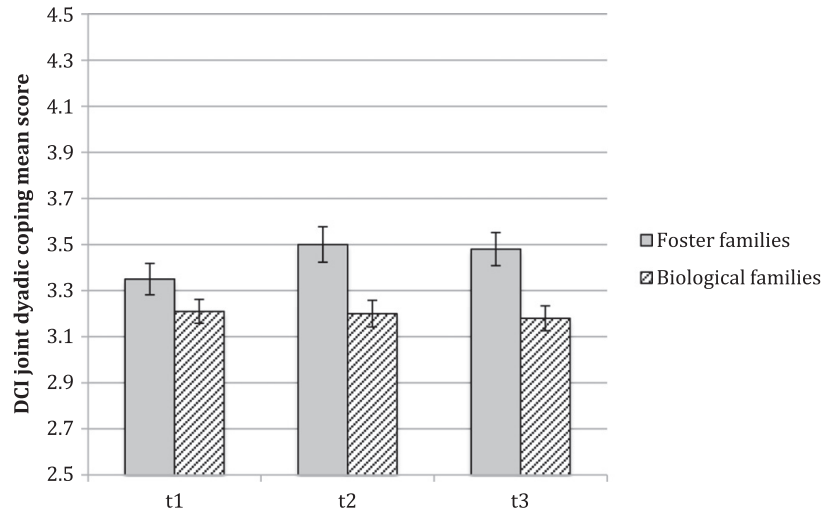

Figure 2. Changes in the joint dyadic coping mean score for foster versus biological families across the three assessments (the error bars show the standard errors of the mean).

The analyses with the children's mental health scores (CBCL) as covariates yielded similar results to those without the covariates, thus the differences in parental DC are independent of differences in child mental health problems between the two samples. While the previous sections were related only to mean differences, the following sections focus on differences regarding the temporal relations between the DC scores of mothers and fathers.

\section{Analysis of Differences Between Foster and Biological Families Regarding the Temporal Relationships Between Maternal and Paternal Dyadic Coping (Hypothesis 2a) and of the Influence of Child Mental Health Problems (Hypothesis 2b)}

Cross-lagged panel analyses were conducted to analyze possible differences in the temporal relationships between maternal and paternal DC (separately for the DC total mean score and the subscale of joint DC; Hypothesis 2a). 


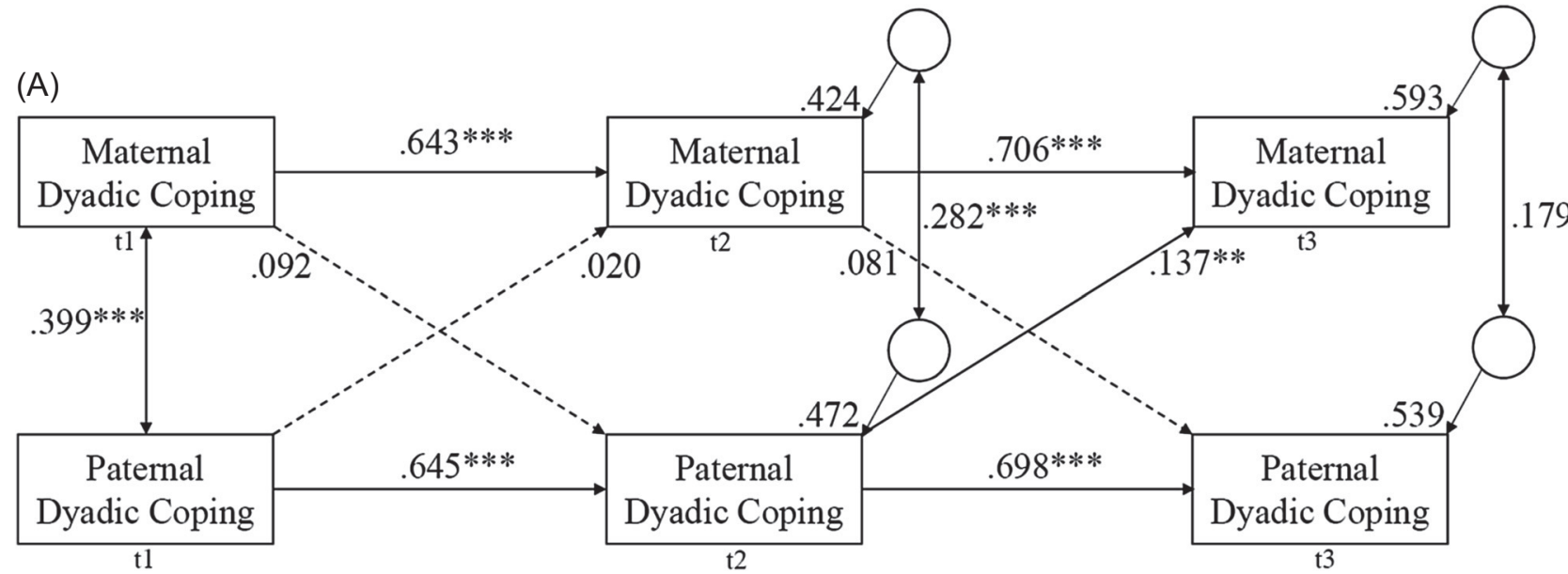

(B)

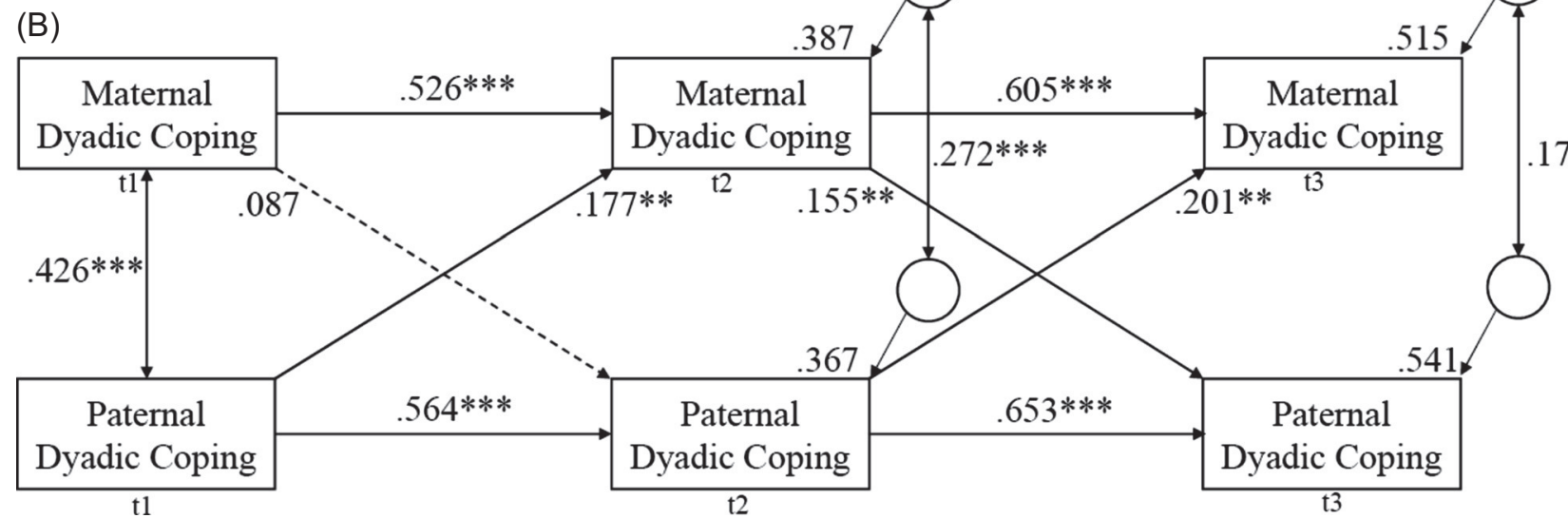

Figure 3. Cross-lagged panel model for (A) the total dyadic coping mean score (combined model for foster and biological families) and (B) for the joint dyadic coping mean score (combined model for foster and biological families with the only substantial group difference being the estimated intercept of paternal dyadic coping at t2: biological families = 1.510; foster families = 1.937). Displayed are standardized values. Arrows represent significant paths $\left({ }^{\star} p<.05 ;{ }^{*} p<.01 ;{ }^{* *} p<.001\right)$, dashed arrows mark nonsignificant paths. Numbers on boxes indicate variance explained $\left(R^{2}\right)$ of the whole model for the respective criterion.

Autoregressive effects (from maternal DC to maternal DC and from paternal DC to paternal DC) account for dependencies across time for one partner (so-called actor effects), cross-lagged effects (so-called partner effects) depict to which extent prior scores of the other partner (e.g., paternal DC at t1) influence the partner's scores at the next assessment (e.g., maternal DC at t2). In lag-1 models with three occasions of measurement, there are four possible crosslagged effects (diagonal effects in Figure 3). To account for associations between mothers' and fathers' DC which may be caused by external factors at each measurement occasion, the models additionally allow the initial scores of parental DC to correlate as well as the residuals of the parental DC scores at $\mathrm{t} 2$ and $\mathrm{t} 3$ (partial correlations).

In an initial step, we tested for group differences in model parameters estimating several multi-group cross-lagged panel models (with biological and foster families representing the groups). Specifically, we first proposed a model with identical structure and parameter values for both groups, and compared this model to less restrictive models allowing for specified group differences. Model fit comparisons allow for identifying the most parsimonious yet fitting model (i.e., the best fitting model representing both groups, compared to two group-specific models). To account for non-normality in the data, we used the MLR-estimator and scaled chisquare test statistic (Satorra \& Bentler, 2010).

Regarding the DC total mean score, cross-lagged panel models with identical model parameters for biological and foster parents fit the data best $\left(\chi^{2}=66.90 ; d f=31 ; p<\right.$ .01 ; CFI $=.93$; RMSEA $=.10$ ) with no less-restrictive model showing superior fit to the data. For reference, the model fit information for the multi-group models with distinct 
estimates for biological and foster families is $\chi^{2}=35.06$; $\mathrm{CFI}=0.95 ; \mathrm{RMSEA}=0.17$. Figure $3 \mathrm{~A}$ presents the model holding in both groups. There are strong autoregressive paths for both, mothers and fathers, reflecting within person (rank) stability over time (actor effects). The initial correlation at $\mathrm{t} 1(r=.399)$ as well as the residual correlations at $\mathrm{t} 2(r=.282)$ and $\mathrm{t} 3(r=.179)$ reflect that the values of both partners are positively related to each other. Only one cross-lagged path coefficient turned significant running from paternal DC (t2) to maternal DC (t3) indicating predictive associations across assessments (partner effect).

The results for the joint DC mean score were similar: The model with group specific intercepts of paternal coping at t2, but otherwise identical parameters (variances, covariances, and regression paths), is the most parsimonious yet best fitting model $\left(\chi^{2}=53.62 ; d f=30 ; p=.01 ; \mathrm{CFI}=.94\right.$; RMSEA $=.08)$. For reference, the model fit information for the multi-group models with distinct estimates for biological and foster families is in this case $\chi^{2}=25.32$; CFI $=0.95$; RMSEA $=0.14$. The selected model showed again strong autoregressive paths $(p<.001)$ and significant bidirectional residual associations within each assessment. Additionally, both diagonal paths from paternal DC to maternal DC and one diagonal path from maternal (t2) to paternal DC (t3) are influential $(p<.01)$. The model for the subscale score of joint coping efforts is shown in Figure 3B.

According to these results, there were no significant differences with regard to the temporal associations of mothers' and fathers' DC scores between the two samples.

To analyze the association between child mental health problems and the parental DC, first, Pearson correlations between the externalizing and internalizing CBCL scores and mothers and fathers DC scores were calculated for each of the three assessments. As shown in Table 2, both CBCL scores proved to be unrelated to the parental DC scores across the three assessments. Second, independent $t$-tests were calculated to compare the DC scores of mothers and fathers depending on whether their child met the criteria for an ICD-10 mental disorder or not (diagnosed with the Kinder-DIPS). Analyses yielded no significant differences depending on the presence of at least one current child mental disorder between the two samples and across the three assessments. The results are summarized in Table 3. Accordingly, child mental health problems were not significantly related to the parental DC skills in the present sample (as was also shown by the previous analyses of covariance).

In order to control for the influences of children's mental health problems on the autoregressive, cross-sectional, and temporal associations between the DC of mothers and fathers in both samples (Hypothesis 2b), we then included either the children's internalizing and externalizing CBCL
Table 2. Pearson correlations ( $r$ ) between mothers' and fathers' dyadic coping mean scores and children's externalizing and internalizing CBCL scores across the three assessments

\begin{tabular}{|c|c|c|c|}
\hline & & $\begin{array}{l}\text { CBCL Externalizing } \\
\text { Behavior Problems }\end{array}$ & $\begin{array}{l}\text { CBCL Internalizing } \\
\text { Behavior Problems }\end{array}$ \\
\hline & & & 1 \\
\hline \multirow[t]{7}{*}{ T1 } & $\mathrm{DCl}$ total score & & \\
\hline & Mothers & -0.04 & \\
\hline & Fathers & 0.02 & 0.00 \\
\hline & $\mathrm{DCl}$ joint dyadic & & \\
\hline & Mothers & 0.10 & 0.10 \\
\hline & Fathers & 0.11 & 0.18 \\
\hline & & & 2 \\
\hline \multirow[t]{7}{*}{$\mathrm{T} 2$} & $\mathrm{DCl}$ total score & & \\
\hline & Mothers & -0.04 & -0.05 \\
\hline & Fathers & 0.10 & 0.05 \\
\hline & DCl joint dyadic & & \\
\hline & Mothers & 0.01 & -0.05 \\
\hline & Fathers & 0.13 & 0.02 \\
\hline & & & 3 \\
\hline \multirow[t]{6}{*}{ T3 } & $\mathrm{DCl}$ total score & & \\
\hline & Mothers & -0.09 & -0.05 \\
\hline & Fathers & 0.02 & 0.04 \\
\hline & $\mathrm{DCl}$ joint dyadic & & \\
\hline & Mothers & -0.09 & -0.05 \\
\hline & Fathers & 0.02 & 0.04 \\
\hline
\end{tabular}

Note. $\mathrm{DCl}=$ Dyadic Coping Inventory (Bodenmann, 2008a); $\mathrm{CBCL}=$ Child Behavior Checklist (Achenbach, 1991; Achenbach \& Rescorla, 2000).

scores or the Kinder-DIPS scores into the cross-lagged panel analyses reported above. For the first alternative, we allowed for both internalizing and externalizing problems at a given measurement occasion to influence both the paternal and maternal DC at the same time point, for each type of family separately. For the second alternative, we analogously allowed for the respective Kinder-DIPS score to influence paternal and maternal DC. For both alternatives, we first evaluated changes in the autoregressive, cross-sectional, and temporal paths between the parents' DC compared to the previous models (see Hypothesis 2a) and the estimated regression coefficients for the children's mental health disorder and health problems. We then compared the initial models with unrestricted associations between $\mathrm{CBCL} /$ Kinder-DIPS values and coping scores to restricted models where the influences of the children's mental disorder or health problems on the DC scores were fixed to zero.

The results of the analyses are shown in Table 4. The initial model analyses showed that controlling for internalizing and externalizing behavior problems or the KinderDIPS did not substantially influence associations between coping scores in either sample. Therefore, we constrained the models to fix the influence of children's mental health 
Table 3. Means (M), standard deviations (SD), and group differences in mothers' and fathers' dyadic coping mean scores depending on the presence of a current child mental disorder across the three assessments

\begin{tabular}{|c|c|c|c|c|c|c|c|}
\hline & \multicolumn{2}{|c|}{$\begin{array}{l}\text { At least one ICD-10 child } \\
\text { mental disorder }\end{array}$} & \multicolumn{2}{|c|}{$\begin{array}{l}\text { No ICD-10 } \text { child mental }^{\text {disorder }}{ }^{1} \\
\end{array}$} & \multirow[b]{2}{*}{$t$} & \multirow[b]{2}{*}{$d f$} & \multirow[b]{2}{*}{$p$} \\
\hline & $n$ & $M(S D)$ & $n$ & $M(S D)$ & & & \\
\hline \multicolumn{8}{|l|}{$\mathrm{T} 1$} \\
\hline \multicolumn{8}{|c|}{$\mathrm{DCl}$ total score } \\
\hline Mothers & 46 & $3.62(0.48)$ & 175 & $3.69(0.50)$ & 0.85 & 219 & .397 \\
\hline Fathers & 45 & $3.62(0.46)$ & 168 & $3.72(0.41)$ & 1.31 & 211 & .193 \\
\hline \multicolumn{8}{|l|}{$\mathrm{DCl}$ joint $\mathrm{DC}$} \\
\hline Mothers & 45 & $3.27(0.63)$ & 170 & $3.24(0.71)$ & -0.27 & 213 & .784 \\
\hline Fathers & 45 & $3.35(0.64)$ & 167 & $3.29(0.61)$ & -0.54 & 210 & .588 \\
\hline \multicolumn{8}{|l|}{ T2 } \\
\hline \multicolumn{8}{|c|}{$\mathrm{DCl}$ total score } \\
\hline Mothers & 41 & $3.63(0.44)$ & 161 & $3.75(0.49)$ & 1.43 & 200 & .155 \\
\hline Fathers & 40 & $3.63(0.50)$ & 153 & $3.70(0.41)$ & 0.95 & 191 & .344 \\
\hline \multicolumn{8}{|l|}{$\mathrm{DCl}$ joint $\mathrm{DC}$} \\
\hline Mothers & 41 & $3.17(0.69)$ & 159 & $3.36(0.77)$ & 1.41 & 198 & .160 \\
\hline Fathers & 40 & $3.33(0.77)$ & 150 & $3.33(0.63)$ & 0.07 & 188 & .944 \\
\hline \multicolumn{8}{|l|}{ T3 } \\
\hline \multicolumn{8}{|c|}{$\mathrm{DCl}$ total score } \\
\hline Mothers & 37 & $3.61(0.46)$ & 159 & $3.74(0.48)$ & 1.51 & 194 & .134 \\
\hline Fathers & 36 & $3.63(0.41)$ & 153 & $3.66(0.44)$ & 0.33 & 187 & .743 \\
\hline \multicolumn{8}{|l|}{$\mathrm{DCl}$ joint $\mathrm{DC}$} \\
\hline Mothers & 35 & $3.30(0.72)$ & 158 & $3.34(0.73)$ & 0.26 & 191 & .796 \\
\hline Fathers & 34 & $3.29(0.61)$ & 152 & $3.27(0.67)$ & -0.15 & 184 & .883 \\
\hline
\end{tabular}

Note. 'Diagnosed with the parent-version of the Kinder-DIPS (Unnewehr et al., 2009); DCI = Dyadic Coping Inventory (Bodenmann, 2008a); DCI mean score range $=1-5 ; d f=$ degrees of freedom; $p=p$-value (2-tailed).

problems on coping scores to zero and compared these and the less constrained models via scaled chi-square test (Satorra \& Bentler, 2010). For both the DC total and the joint DC mean score the model comparisons showed that fixing the influence of children's mental health problems on coping scores to zero did not lead to significantly decreased model fit (see Table 4). We therefore conclude that children's mental health problems, measured dimensionally by the CBCL or rather categorically by the Kinder-DIPS, do not substantially influence DC in the present study.

\section{Prediction of Child Mental Health Problems by Parental Dyadic Coping (Hypothesis 3)}

Preliminary analyses were conducted to ensure no violation of the assumptions of outliers and multicollinearity for both, the hierarchical multiple and the logistic regressions, as well as of normality, linearity, and homoscedasticity of the residuals for the hierarchical multiple regressions. The following analyses again were conducted separately for the DC total mean score and the subscale of joint DC. In all regression analyses family type (foster vs. biological families) was entered in Step 1 to account for the differences in child mental health problems between the two samples. In the following, we not only wanted to test the influence of the mothers' and fathers' initial DC scores at t1 but also of the change in the parental DC over time. At step 2, we therefore entered both the DC scores at $\mathrm{t} 1$ as well as the unstandardized residuals of the regression analyses of the DC scores from $t 1$ to $t 2$ and from $t 2$ to $t 3$ into the analyses.

With regard to outliers of the DC total mean score, the joint DC mean score, and the CBCL externalizing and internalizing scales, preliminary analyses yielded zero to two values outside three standard deviations from the mean. In order not to reduce sample size, for the following analyses each outlier was replaced by the sum of the respective mean score plus three standard deviations. After inspecting the regression residuals for outliers, we had to remove additional cases from each of the analyses. All analyses were also calculated with the full sample, but yielded similar results. In the following, we therefore only report the results for the reduced sample. Tables 5 and 6 
Table 4. Comparisons of models including and excluding influence of children's mental health problems on parental dyadic coping

\begin{tabular}{|c|c|c|c|c|c|c|c|c|c|}
\hline & \multicolumn{3}{|c|}{ Less constrained model ${ }^{a}$} & \multicolumn{3}{|c|}{ Constrained model ${ }^{b}$} & \multicolumn{3}{|c|}{ Model comparison $^{c}$} \\
\hline & $\chi^{2}(d f, p)$ & $\mathrm{CFI}$ & $\overline{\mathrm{SRMR}}$ & $\chi^{2}(d f, p)$ & $\mathrm{CFI}$ & $\overline{\text { SRMR }}$ & $\Delta \chi^{2}$ & $\Delta d f$ & $p$-value \\
\hline \multicolumn{10}{|l|}{ CBCL scores } \\
\hline $\mathrm{DCl}$ total score & $106.331(56,<.001)$ & 0.921 & 0.039 & $120.616(80, .002)$ & 0.972 & 0.062 & 14.723 & 24 & .929 \\
\hline $\mathrm{DCl}$ joint $\mathrm{DC}$ & $81.118(56, .016)$ & 0.949 & 0.046 & $103.067(80, .042)$ & 0.982 & 0.069 & 22.336 & 24 & .559 \\
\hline \multicolumn{10}{|l|}{ Kinder-DIPS scores } \\
\hline DCl total score & $64.021(32, .001)$ & 0.950 & 0.049 & $79.734(44, .001)$ & 0.948 & 0.085 & 16.622 & 12 & .164 \\
\hline $\mathrm{DCl}$ joint $\mathrm{DC}$ & $57.038(32, .004)$ & 0.948 & 0.047 & $68.704(44, .010)$ & 0.955 & 0.068 & 12.449 & 12 & .410 \\
\hline
\end{tabular}

Note. Estimator: MLR. ${ }^{a}$ Model with freely estimated regression weights of children's mental health problems on parental dyadic coping. ${ }^{\text {} M o d e l ~ w i t h ~}$ regression weights of children's mental health problems on parental dyadic coping fixed to zero. 'Scaled and adjusted $\chi^{2}$-difference value according to Satorra and Bentler (2010).

Table 5. Summary of the hierarchical multiple regressions for the prediction of child externalizing and internalizing behavior problems (CBCL) at t3 separately for the total dyadic coping mean score and the subscale of joint dyadic coping

\begin{tabular}{|c|c|c|c|c|c|c|c|c|c|c|c|c|}
\hline \multirow[b]{3}{*}{ Predictor } & \multicolumn{12}{|c|}{ Total dyadic coping } \\
\hline & \multicolumn{6}{|c|}{ Externalizing behavior problems } & \multicolumn{6}{|c|}{ Internalizing behavior problem } \\
\hline & $N$ & $R^{2}$ & $b$ & SE B & $\beta$ & $p$ & $N$ & $R^{2}$ & $b$ & SE B & $\beta$ & $p$ \\
\hline Step 1 & 172 & 0.11 & & & & $\leq .001 * * *$ & $171^{1}$ & 0.05 & & & & $.003 \star \star$ \\
\hline Constant & & & 47.00 & 0.98 & & $\leq .001 * * \star$ & & & 45.30 & 0.91 & & $\leq .001 * * *$ \\
\hline Group & & & 7.32 & 1.59 & 0.334 & $\leq .001 * * \star$ & & & 4.42 & 1.48 & 0.224 & $.003 * \star$ \\
\hline Step 2 & & 0.15 & & & & $\leq .001 * \star \star$ & & 0.07 & & & & .106 \\
\hline Constant & & & 51.57 & 7.77 & & $\leq .001 * * \star$ & & & 49.67 & 7.29 & & $\leq .001 * * \star$ \\
\hline Group & & & 7.70 & 1.63 & 0.351 & $\leq .001 * \star \star$ & & & 4.69 & 1.53 & 0.238 & $.003 \star \star$ \\
\hline Total DC t1 $q$ & & & -1.58 & 1.77 & -0.075 & .376 & & & -1.53 & 1.66 & -0.081 & .359 \\
\hline Total DC t1 $\hat{o}$ & & & 0.30 & 2.05 & 0.012 & .885 & & & 0.32 & 1.92 & 0.014 & .869 \\
\hline Res t1-t2 우 & & & -1.56 & 2.37 & -0.053 & .511 & & & -1.22 & 2.23 & -0.046 & .584 \\
\hline Res $\mathrm{t} 1-\mathrm{t} 2 \hat{\mathrm{o}}$ & & & -1.16 & 2.62 & -0.034 & .659 & & & -0.71 & 2.47 & -0.023 & .775 \\
\hline Res t2-t3 + & & & -5.34 & 2.87 & -0.148 & .065 & & & -2.32 & 2.69 & -0.072 & .390 \\
\hline \multirow[t]{3}{*}{ Res t2-t3 ô } & & & 1.63 & 2.75 & 0.045 & .553 & & & 2.13 & 2.58 & 0.065 & .409 \\
\hline & \multicolumn{12}{|c|}{ Joint dyadic coping } \\
\hline & \multicolumn{6}{|c|}{ Externalizing behavior problems } & \multicolumn{6}{|c|}{ Internalizing behavior problems } \\
\hline Predictor & $N$ & $R^{2}$ & $b$ & SE B & $\beta$ & $p$ & $N$ & $R^{2}$ & $b$ & SE B & $\beta$ & $p$ \\
\hline Step 1 & 165 & 0.10 & & & & $\leq .001 * * *$ & $163^{2}$ & 0.05 & & & & $.006 * \star$ \\
\hline Constant & & & 47.00 & 0.97 & & $\leq .001 * \star \star$ & & & 45.30 & 0.89 & & $\leq .001 * \star *$ \\
\hline Group & & & 6.79 & 1.63 & 0.311 & $\leq .001 * * *$ & & & 4.24 & 1.53 & 0.214 & $.006^{\star \star}$ \\
\hline Step 2 & & 0.14 & & & & $\leq .001 * * *$ & & 0.12 & & & & $.007 * \star$ \\
\hline Constant & & & 42.29 & 5.07 & & $\leq .001 * * *$ & & & 34.44 & 4.65 & & $\leq .001 * * *$ \\
\hline Group & & & 7.18 & 1.70 & 0.328 & $\leq .001 * \star \star$ & & & 4.53 & 1.57 & 0.229 & $.004^{\star \star}$ \\
\hline Joint DC t1 ㅇ & & & -0.33 & 1.32 & -0.021 & .804 & & & 1.17 & 1.22 & 0.084 & .338 \\
\hline Joint DC t1 $\widehat{o}$ & & & 1.71 & 1.47 & 0.097 & .247 & & & 2.11 & 1.35 & 0.133 & .120 \\
\hline Res t1-t2 q & & & -1.97 & 1.49 & -0.108 & .189 & & & -3.04 & 1.37 & -0.184 & $.028 *$ \\
\hline Res t1-t2 ô & & & 0.09 & 1.60 & 0.005 & .956 & & & -1.09 & 1.47 & -0.064 & .458 \\
\hline Res $\mathrm{t} 2-\mathrm{t} 3$ 우 & & & -3.69 & 1.67 & -0.179 & $.028 *$ & & & -2.49 & 1.53 & -0.135 & .104 \\
\hline Res t2-t3 $\hat{\jmath}$ & & & -0.61 & 1.89 & -0.025 & .749 & & & 0.80 & 1.73 & 0.037 & .644 \\
\hline
\end{tabular}

Note. Group: 0 = biological families; 1 = foster families; $\rho$ = mothers; $\hat{o}=$ fathers. Res = unstandardized residuals of the regression analysis; removed number of residual outliers: ${ }^{1} n=1 ;{ }^{2} n=2 .{ }^{* *} p<.001,{ }^{* *} p<.01,{ }^{*} p<.05$ (2-tailed).

provide the estimates of the hierarchical linear and logistic regressions analyses, respectively.

With regard to externalizing behavior problems (CBCL) all determination coefficients of the multiple regression models turned out to be significant $(p \leq .001)$. The model with total DC explained $15 \%$ of variance and the model with joint DC $14 \%$ of variance. As can be seen in Table 5, in both analyses, most of the variance was explained by the 
Table 6. Summary of the logistic regression for the prediction of the presence of an ICD-10 child mental disorder (Kinder-DIPS) at t3 separately for the total dyadic coping mean score and the subscale of joint dyadic coping

\begin{tabular}{|c|c|c|c|c|c|c|c|c|c|}
\hline & \multicolumn{9}{|c|}{ Total dyadic coping } \\
\hline & \multirow[b]{2}{*}{$N$} & \multirow[b]{2}{*}{$b$} & \multirow[b]{2}{*}{ SE B } & \multirow[b]{2}{*}{ Wald } & \multirow[b]{2}{*}{$d f$} & \multirow[b]{2}{*}{$p$} & \multirow[b]{2}{*}{ Odds } & \multicolumn{2}{|c|}{$95 \% \mathrm{Cl}$ for OR } \\
\hline & & & & & & & & Lower & Upper \\
\hline \multicolumn{10}{|l|}{ Step 1} \\
\hline Group & $174^{1}$ & 1.90 & 0.50 & 14.44 & 1 & $\leq .001 * * \star$ & 6.67 & 2.51 & 17.74 \\
\hline Constant & & -2.73 & 0.42 & 41.98 & 1 & $\leq .001 * \star \star$ & 0.07 & & \\
\hline \multicolumn{10}{|l|}{ Step 2} \\
\hline Constant & & 2.37 & 2.47 & 0.92 & 1 & .339 & 10.67 & & \\
\hline Group & & 2.26 & 0.56 & 16.11 & 1 & $\leq .001 * \star \star$ & 9.54 & 3.17 & 28.69 \\
\hline$M$ o-t1 & & -1.05 & 0.60 & 3.40 & 1 & .065 & 0.35 & 0.12 & 1.07 \\
\hline$M \hat{\delta}-\mathrm{t} 1$ & & -0.45 & 0.63 & 0.52 & 1 & .471 & 0.64 & 0.19 & 2.17 \\
\hline $\operatorname{Res} M$ + $-\mathrm{t} 2$ & & -1.39 & 0.76 & 3.41 & 1 & .065 & 0.25 & 0.06 & 1.09 \\
\hline $\operatorname{Res} M \hat{\jmath}-t 2$ & & 1.60 & 0.89 & 3.25 & 1 & .071 & 4.94 & 0.87 & 28.03 \\
\hline Res $M$ O-t3 & & -0.73 & 0.90 & 0.66 & 1 & .416 & 0.48 & 0.08 & 2.80 \\
\hline \multirow[t]{4}{*}{$\operatorname{Res} M \hat{\sigma}-\mathrm{t} 3$} & & 0.02 & 0.88 & 0.00 & 1 & .978 & 1.02 & 0.18 & 5.75 \\
\hline & \multicolumn{9}{|c|}{ Joint dyadic coping } \\
\hline & & & & & & & & \multicolumn{2}{|c|}{$95 \% \mathrm{Cl}$ for OR } \\
\hline & $N$ & $b$ & SE B & Wald & $d f$ & $p$ & Odds & Lower & Upper \\
\hline \multicolumn{10}{|l|}{ Step 1} \\
\hline Group & $158^{2}$ & 1.88 & 0.51 & 13.80 & 1 & $\leq .001 * \star \star$ & 6.57 & 2.43 & 17.75 \\
\hline Constant & & -2.73 & 0.42 & 41.98 & 1 & $\leq .001 * \star \star$ & 0.07 & & \\
\hline \multicolumn{10}{|l|}{ Step 2} \\
\hline Constant & & -3.35 & 1.61 & 4.30 & 1 & $.038 *$ & 0.04 & & \\
\hline Group & & 2.00 & 0.55 & 13.41 & 1 & $\leq .001 * \star \star$ & 7.37 & 2.53 & 21.46 \\
\hline$M_{+}$-t1 & & -0.26 & 0.43 & 0.36 & 1 & .546 & 0.77 & 0.33 & 1.79 \\
\hline$M \hat{\delta}-\mathrm{t} 1$ & & 0.40 & 0.46 & 0.76 & 1 & .383 & 1.49 & 0.61 & 3.63 \\
\hline Res $M$ क-t2 & & -0.67 & 0.46 & 2.13 & 1 & .145 & 0.51 & 0.21 & 1.26 \\
\hline Res $M$ o-t2 & & 0.57 & 0.51 & 1.26 & 1 & .262 & 1.76 & 0.65 & 4.75 \\
\hline Res $M$ q-t3 & & -0.25 & 0.52 & 0.23 & 1 & .633 & 0.78 & 0.28 & 2.15 \\
\hline Res $M$ ô-t3 & & -0.49 & 0.60 & 0.67 & 1 & .414 & 0.61 & 0.19 & 1.98 \\
\hline
\end{tabular}

Note. Group: 0 = biological families, 1 = foster families; $M=$ mean score; $q=$ mothers; $\hat{\sigma}=$ fathers; Res $=$ unstandardized residuals of the regression analysis; $\mathrm{Cl}=$ Confidence Interval; $\mathrm{OR}=$ odds ratio; $\chi^{2}=$ omnibus chi-square score. Removed number of residual outliers: ${ }^{1} n=7 ;{ }^{2} n=7 .{ }^{\star} \star \star p<.001$, ${ }^{\star \star} p<.01,{ }^{\star} p<.05$ (2-tailed).

type of family (biological vs. foster family). After entry of mothers' and fathers' DC scores at $\mathrm{t} 1$ and the unstandardized regression residuals from $\mathrm{t} 1$ to $\mathrm{t} 2$ and from $\mathrm{t} 2$ to $\mathrm{t} 3$ both models only explained $4 \%$ of additional variance. While family type was the only significant predictor in the analysis employing total DC, in the analysis employing joint DC two predictors, family type and the mothers' regression residuals from $t 2$ to $t 3$, were significant. However, in both regression analyses, the increase in $R^{2}$ was statistically not significant $(p \geq .283)$.

With regard to internalizing behavior problems (CBCL) again both Step 1 models $(p \leq .003)$ but only the Step 2 model employing joint DC had statistically significant determination coefficients $(p=.007)$, the Step 2 model employing total DC had not $(p=.106)$. The Step 2 model with total DC explained $7 \%$ of variance with no significant predictor besides family type and the change in $R^{2}(+2 \%)$ was not significant $(p=.770)$. The Step 2 model with joint DC explained $12 \%$ of variance, but still, the increase in $R^{2}$ of about $7 \%$ by adding the joint DC to the model was not significant $(p=.066)$. Besides family type, the mothers' regression residuals from t 1 to 2 were another significant predictor.

In total, only few DC scores were significant predictors for child externalizing or internalizing behavior problems and explained only little additional variance.

In the stepwise logistic regression analysis to predict the presence of a child mental disorder (Kinder-DIPS) by family type and the mothers' and fathers' total DC the model with family type as the only predictor (Step 1) already was significant $\left(\chi^{2}=17.3 ; d f=1 ; p \leq .001\right)$. The model accounted for between 10\% (Cox and Snell $R^{2}$ ) and 17\% (Nagelkerke $R^{2}$ ) 
of variance in child mental health status and successfully predicted $100 \%$ of the children without but $0 \%$ with a mental disorder. The values of the coefficients shown in Table 6 reveal that being a foster child was associated with an increase in the odds of having a child mental disorder by a factor of 6.67 (95\% CI [2.51, 17.74]). The Step 2 model also significantly predicted the presence of a child mental disorder (full model: $\chi^{2}=29.72 ; d f=7 ; p \leq .001$ ); however, the increase in the proportion of explained variance was narrowly not significant $\left(\chi^{2}=12.42 ; d f=6 ; p=.053\right)$. Accordingly, adding the mothers' and fathers' total DC to the model did not significantly improve the prediction of the dependent variable. The Step 2 model accounted for between $17 \%$ and $28 \%$ of variance and successfully predicted $99 \%$ of the children without and $19 \%$ with a mental disorder (86\% in total). In both Step models family type was the only significant predictor (cf. Table 6).

In the Step 1 model of the stepwise logistic regression analysis to predict the presence of a child mental disorder by family type and the mothers' and fathers' joint DC again, family type (biological vs. foster family) was a significant predictor $\left(\chi^{2}=16.17, d f=1, p \leq .001\right)$. The model accounted for between $10 \%$ and $17 \%$ of the variance and successfully predicted $100 \%$ of the children without but $0 \%$ of children with a mental disorder ( $85 \%$ in total). In this case, being a foster child was associated with an increase in the odds of having a child mental disorder by a factor of 6.57 (95\% CI $[2.43,17.75])$. The Step 2 model also significantly predicted the presence of a child mental disorder (full model: $\chi^{2}=20.84 ; d f=7 ; p=.004$ ), however, the increase in the proportion of explained variance was again not significant $\left(\chi^{2}=4.67 ; d f=6 ; p=.587\right)$. Accordingly, adding the mothers' and fathers' joint DC to the model also did not significantly improve the prediction of the dependent variable. This time the Step 2 model accounted for between $12 \%$ and $22 \%$ of the variance and successfully predicted $97 \%$ of the children without and $4 \%$ with a mental disorder (83\% in total). Family type was the only significant predictor in both models; thus the parents' joint DC did not significantly predict the presence of a child mental disorder.

\section{Discussion}

\section{Differences Between Foster and Biological Parents Regarding Dyadic Coping}

The present study was the first to investigate DC in foster parents and its association to child mental health problems over a period of 1 year and to compare the results to biological parents. In earlier publications, the foster children of the present sample were found to show significantly more externalizing and internalizing behavior problems compared to the biological children and the foster parents were found to report significantly increased parental stress experiences compared to the biological parents (Lohaus et al., 2017). Despite these differences to the detriment of the foster families, in the present investigation, foster parents were found to report significantly better DC competencies than the biological parents at all times of assessment (Hypothesis 1). This was also true if the children's mental health scores (CBCL) were included in the analyses as covariates. With regard to the joint DC, the foster parents even showed an increase over time while the report of the biological parents remained unchanged (see Figure 2). Although raising a foster child may be a lot more challenging and related to more parenting stress than raising one's own biological child, this does not seem to have a negative impact on the parental DC competencies. Foster parents deliberately and jointly decide to take care of a foster child. Accordingly, similar to the parents of children with a Down syndrome (Gabriel et al., 2005), they may expect their foster child to show challenging behavior, which in turn may lead to an increased DC. Another explanation may be that foster parents already had increased DC competencies before they decided to take care of a foster child. There are some selection criteria for people who want to become foster parents in Germany, for example, a certain level of financial security and high resilience. It is quite possible that parents who meet these criteria more often have a stable relationship or get additional training or supervision before and after becoming foster parents. Therefore, they might feel more confident to jointly cope with the increased stress experiences related to raising a foster child. While biological parents are more often surprised by significant child emotional and behavior problems (Zimet \& Jacob, 2001), foster parents with increased DC competencies may be better able to join forces to successfully cope with these challenges as a couple. Finally, foster parents might also perceive the stress due to the child's difficulties as less severe compared to biological parents because biological parents may feel guilty as they may (incorrectly or correctly) perceive themselves to be responsible for their child's difficulties. The foster children of the current investigation already lived on average 17.6 months in their foster family. Future research should start to assess the DC of foster parents' DC competencies from the moment of the decision making to take care of a foster child to answer the question whether these dyads show better DC competencies right from the start or if they develop better DC competencies over time, and to explore mechanisms of change in comparison to normative samples.

Although there may be different explanations for the increased DC competencies in foster parents, the mutual parental support can be seen as a protective factor in these 
families. Good DC competencies may increase family stability and thus prevent foster children from future relationship breakups and placement disruptions. This seems quite important because placement disruptions, in particular, put foster children to a greater risk of a worse child development (Rubin, O’Reilly, Luan, \& Localio, 2007). Low DC competencies, on the other hand, are associated with relationship discord in couples (e.g., Hilpert et al., 2013, 2016) and may lead to relationship breakups and divorce (Bodenmann, 2008b). Relationship breakup and divorce of foster parents may be followed by relationship breakups for the foster child (e.g., because one parent moves out of the joint home) or even a placement disruption (e.g., because divorced parents may not feel able to care for a foster child anymore).

\section{Maternal and Paternal Dyadic Coping and Their Relation to Children's Mental Health}

With regard to the associations between maternal and paternal DC in the two samples (Hypothesis 2a) crosslagged panel analyses yielded models with identical model parameters both, for the total DC and the joint DC (with the exception of the intercept for paternal joint DC at t2). The main conclusion from these analyses is that there are no significant differences between the foster and the biological families with regard to the temporal relation between maternal and paternal DC efforts across the three assessments. Apart from that, the models (see Figure 3) showed that there are strong within person associations (actor effects) of the DC competencies for both, (foster) mothers and fathers, over time. With regard to partner effects, the analyses yielded one significant path from the fathers' DC score at $\mathrm{t} 2$ to the mothers' score at $\mathrm{t} 3$ for the total DC, and three significant paths from the fathers' scores at $t 1$ or rather $\mathrm{t} 2$ to the mothers' scores each at the next assessment, and from the mothers' score at $\mathrm{t} 2$ to the fathers' score at $\mathrm{t} 3$ for the joint DC. In total, the paternal DC scores seem to have a greater influence on the maternal DC than vice versa. However, at least with regard to the joint DC, the influence of the maternal DC on the fathers' rating at the next assessment seems to develop over time in both types of families. At this point longer follow-ups are needed to investigate whether this trend will continue over time.

Unexpectedly, the (foster) children's mental health problems were found to be completely unrelated to the parental DC efforts, both at the different times of assessment as well as with regard to the temporal associations between the maternal and paternal DC across time (Hypothesis 2b). This result deviates from earlier findings, where parents of a child with significant behavior problems were found to report less DC competencies compared to parents of a healthy child (e.g., Gabriel \& Bodenmann, 2006a; Zemp, Bodenmann, Backes, et al., 2016). An important difference between the present study and the previous ones may be the way the stress experience is approached: while in previous studies, the child behavior problems may have been unexpected (occurring either spontaneously during normal development or somewhat expected after unexpectedly learning about a developmental disability of the child), foster parents may deliberately approach this additional stress as partners. So far, the literature on DC has primarily focused on coping with accidental stressors, such as an illness. The results of the present study may provide some initial evidence that it may be important to conceptually include a link between previous (partner) agency and later (dyadic) stress management in the sense that a deliberate and well-thought previous action, such as taking a child into one's family, may be associated with different DC processes than stress experiences that are evoked by other actions. Conceptually elaborating on this difference may help identify further moderator or mediators of DC, including for example the sense of control over the elicitation process, or the significance of the decision to jointly approach extra stress as a couple.

\section{Prediction of Children's Mental Health Scores by Maternal and Paternal Dyadic Coping}

The regression models (Hypothesis 3) showed that, besides the family type (biological vs. foster family), the mothers' and fathers' DC scores in general did not significantly predict child mental health problems at $\mathrm{t} 3$ or only accounted for a small proportion of additional variance in both family types. These mainly nonsignificant results with regard to the parental DC may be due to a low variance of the DC scores in the present sample or may indicate that there is a large variance with regard to the individual associations between the DC and child mental health problems across families that are not adequately reflected in mean values. Another explanation may be that the association between the two variables only emerges in older children (e.g., school age children, but not preschool children). The reason could be that mental health problems may be more apparent for parents as the children get older. Schermerhorn, Cummings, De Carlo, and Davies (2007), for example, investigated 232 families with children aged 5-7 years over a 3-year period. They found that destructive couple conflict at baseline significantly predicted child behavior problems 1 year later (t2), but also that child behavior problems at t2 significantly predicted the extent of couple conflict another year later. While the earlier research, for example, by Schermerhorn et al. (2007) and Zemp, Bodenmann, Backes, et al. (2016), was conducted with families with 
mainly school aged children and adolescents, the foster and biological children of the present investigation were mainly of preschool age. At this point, again, longer follow-ups are needed to track the development of the DC of (foster) parents and its association with child mental health problems over a longer period of time. If we assume the association between child mental health problems and the parental DC to develop with the child's age, the promotion and maintenance of parental DC competencies in (foster) families with preschool aged (foster) children could be a promising starting point for preventive interventions. When taking into account the partner effects of the cross-lagged panel models, especially those from the paternal to the maternal DC across the assessments, it seems particularly important to find ways to involve both, (foster) mothers and fathers in preventive efforts to increase parental DC and strengthen the long-term parental relationship (see also Bodenmann et al., 2016). Finally, the idea that a deliberate approach to stress as a couple may impact the subsequent DC process would also be in line with the present nonsignificant results.

\section{Strengths and Limitations}

Strengths of the present investigation are (a) the inclusion of two samples, a sample of foster families and a comparison group with biological families, (b) the inclusion of the perspectives of both, mothers and fathers separately, with regard to their DC competencies, (c) the assessment of child psychopathology with both, a dimensional questionnaire (CBCL) as well as a more objective, standardized clinical interview (Kinder-DIPS), and (d) the availability of longitudinal data with three assessments.

When interpreting the results, however, some limitations need to be taken into account: While the questionnaire on parental DC was filled out by mothers and fathers separately, the CBCL and the Kinder-DIPS were mainly based on only one perspective (typically the mothers' report). This can lead to increased associations between the maternal assessments due to single source bias (Little, 2014; Lohaus et al., 2017). As Table 2 shows, the correlations between mothers' and fathers' DC and the CBCL scores are quite similar. Nevertheless, fathers could have rated their child's behavior differently from mothers. For future research, we therefore recommend to assess both, the DC as well as the measures on child psychopathology, from both parents at the same time. With regard to the interpretation of the Kinder-DIPS results, it should be taken into account that we only examined whether a child met the criteria for at least one ICD-10 mental disorder across the three assessments or not. Based on previous research, it can be assumed that different types of mental disorders (e.g., externalizing vs. internalizing), different degrees of severity, and comorbidity may have a different impact on the parental DC (e.g., Gabriel \& Bodenmann, 2006b). To avoid too small sample sizes, however, we did not distinguish between different types of mental disorders, degrees of severity, comorbidity, or changes in diagnoses over time. This issue should be addressed in future research and with larger samples. Another limitation of the present investigation is the reliance on parent report measures. The assessment of reliable child reports in preschool aged children, however, is hardly possible. Further options for future research could be to use objective behavior observations to quantify the DC competencies of parents (e.g., Zemp, Bodenmann, Backes, et al., 2016) and to use the report of kindergarten teachers as another source to assess child mental health problems. We furthermore have to assume that our foster families might be a selective sample of families who were willing to participate in a longitudinal study. It should also be noted that the goodness of fit indices for the final cross-lagged panel models do not indicate consistently good fit. While the CFI-values indicate good model fits, the RMSEA indices show misfit (especially for the DC total mean score). However, since our aim was to find the most parsimonious model for both biological and foster families, which does not fit the data significantly worse than the unconstrained model with individual estimates for both samples, we decided to report these models with mixed overall fit results. The multi-group models with distinct estimates for biological and foster families would have been difficult to interpret meaningfully. Hence, the interpretation of our results should take into account the comparative nature of our model reports. Future studies are needed to replicate the results of the present work, especially with regard to the prediction models and the longitudinal structure of parental DC including additional model alternatives.

\section{Conclusion}

Besides these limitations, the present investigation makes an important contribution to the research on the DC in foster families with young foster children compared to biological families and on how child mental health problems affect the parental DC. Foster children have an increased risk to develop mental health problems (Vasileva \& Petermann, 2018) that tend to persist into adulthood (Teyhan et al., 2018). Besides the mainly nonsignificant results with regard to the associations between the parental DC and the child mental health indicators, the promotion and maintenance of high DC competencies, especially in foster parents, might still be a promising approach at least to enhance family stability of (foster) families. However, more research is needed to derive starting points to support 
(foster) families with children with significant child mental health problems.

\section{Electronic Supplementary Material}

ESM 1. Foster (Table E1) and biological (Table E2) mothers' and fathers' means $(M)$ and standard deviations $(S D)$ for the sum scores of all DCI sub-scales across the three assessments. Table E3 shows the analysis of variance for the DC scores (total and joint mean score) in dependence of group (foster vs. biological), sex of partner (maternal vs. paternal assessment), and time of assessment.

\section{References}

Achenbach, T. M. (1991). Manual of the Child Behavior Checklist/ 4-18 and 1991 profile. Burlington, VT: University of Vermont, Department of Psychiatry.

Achenbach, T. M., \& Rescorla, L. (2000). CBCL/1.5-5 \& TRF/1.5-5 profiles. Burlington, $\mathrm{VT}$ : University of Vermont, Department of Psychiatry.

Amato, P. R. (2010). Research on divorce: Continuing trends and new developments. Journal of Marriage and Family, 72, 650-666. https://doi.org/10.1111/j.1741-3737.2010.00723.x

Bodenmann, G. (2000). Stress und Coping bei Paaren [Stress and coping in couples]. Göttingen, Germany: Hogrefe.

Bodenmann, G. (2004). Verhaltenstherapie mit Paaren: Ein modernes Handbuch für die psychologische Beratung und Behandlung [Behavior therapy with couples. A modern handbook for psychological counseling and treatment]. Bern, Switzerland: Huber.

Bodenmann, G. (2008a). Dyadisches Coping Inventar: Test manual [Dyadic Coping Inventory: Test manual]. Bern, Switzerland: Huber.

Bodenmann, G. (2008b). Dyadic coping and the significance of this concept for prevention and therapy. Zeitschrift für Gesundheitspsychologie, 16, 108-111. https://doi.org/10.1026/0943-8149. 16.3.108

Bodenmann, G., Randall, A. K., \& Falconier, M. K. (2016). Coping in couples: the Systemic Transactional Model (STM). In M. K. Falconier, A. K. Randall, \& G. Bodenmann (Eds.), Couples Coping with Stress: A cross-cultural perspective (pp. 5-22). New York, NY: Routledge.

Briggs-Gowan, M. J., Horwitz, S. M., Schwab-Stone, M. E., Leventhal, J. M., \& Leaf, P. J. (2000). Mental health in pediatric settings: Distribution of disorders and factors related to service use. Journal of the American Academy of Child and Adolescent Psychiatry, 39, 841-849. https://doi.org/10.1097/00004583200007000-00012

Brock, R. L., \& Kochanska, G. (2016). Interparental conflict, children's security with parents, and long-term risk of internalizing problems: A longitudinal study from ages 2 to 10 . Development and Psychopathology, 28, 45-54. https://doi.org/ 10.1017/S0954579415000279

Burns, B. J., Phillips, S. D., Wagner, H. R., Barth, R. P., Kolko, D. J., Campbell, Y., \& Landsverk, J. (2004). Mental health need and access to mental health services by youths involved with child welfare: A national survey. Journal of the American Academy of Child and Adolescent Psychiatry, 43, 960-970. https://doi.org/ 10.1097/01.chi.0000127590.95585.65

Chamberlain, P., Price, J. M., Reid, J. B., Landsverk, J., Fisher, P. A., \& Stoolmiller, M. (2006). Who disrupts from placement in foster and kinship care? Child Abuse \& Neglect, 30, 409-424. https://doi.org/10.1016/j.chiabu.2005.11.004

Chandler, C. L., \& Sanders, M. R. (2013). Taking Care Triple P Positive Parenting Program for out-of-home care providers workbook for use with children up to 12 years old. Brisbane, Australia: University of Queensland.

Cina, A., \& Bodenmann, G. (2009). Zusammenhang zwischen Stress der Eltern und kindlichem Problemverhalten [Relationship between parental stress and child problem behavior]. Kindheit und Entwicklung, 18, 39-48. https://doi.org/10.1026/ 0942-5403.18.1.39

Cummings, E. M., \& Davies, P. T. (2010). Marital conflict and children: An emotional security perspective. New York, NY: Guilford Press.

Feinberg, M. E. (2002). Coparenting and the transition to parenthood: A framework for prevention. Clinical Child and Family Psychology Review, 5, 173-195. https://doi.org/10.1023/ A:1019695015110

Feinberg, M. E., Jones, D. E., Hostetler, M. L., Roettger, M. E., Paul, I. M., \& Ehrenthal, D. B. (2016). Couple-focused prevention at the transition to parenthood, a randomized trial: effects on coparenting, parenting, family violence, and parent and child adjustment. Prevention Science, 17, 751-764. https://doi.org/ 10.1007/s11121-016-0674-z

DiNardo, P. A., \& Barlow, D. A. (1988). Anxiety Disorders Interview Schedule Revised (ADIS-R). Albany, NY: Centers for Stress and Anxiety Disorders.

Gabriel, B., \& Bodenmann, G. (2006a). Befinden, Partnerschaftsund Elternzufriedenheit bei Eltern im Zusammenhang mit kindlichem Verhalten [Association of child behavior with wellbeing, marital, and parenting satisfaction in parents]. Psychologie in Erziehung und Unterricht, 53, 213-225.

Gabriel, B., \& Bodenmann, G. (2006b). Stress und Coping bei Paaren mit einem verhaltensauffälligen Kind [Stress and coping in parents of a child with behavioral problems]. Zeitschrift für klinische Psychologie und Psychotherapie, 35, 59-64. https://doi.org/10.1026/1616-3443.35.1.59

Gabriel, B., \& Bodenmann, G. (2006c). Elterliche Kompetenzen und Erziehungskonflikte: Eine ressourcenorientierte Betrachtung von familiären Negativdynamiken [Parental competencies and conflicts related to parenting: A resource-oriented view of negative dynamics in families]. Kindheit und Entwicklung, 15, 9-18. https://doi.org/10.1026/0942-5403.15.1.9

Gabriel, B., Zeender, N., \& Bodenmann, G. (2005). Stress und Coping bei Eltern von Kindern mit externalisierenden Verhaltensauffälligkeiten, Down-Syndrom und angemessener Entwicklung: Welche Rolle spielt das dyadische Coping? [Stress and coping in parents of children with conduct problems, Down's syndrome, and normal development: The role of dyadic coping] Zeitschrift für klinische Psychologie. Psychiatrie und Psychotherapie, 52, 315-327.

Goemans, A., van Geel, M., \& Vedder, P. (2015). Over three decades of longitudinal research on the development of foster children: A meta-analysis. Child Abuse \& Neglect, 42, 121-134. https:// doi.org/10.1016/j.chiabu.2015.02.003

Hilpert, P., Bodenmann, G., Nussbeck, F. W., \& Bradbury, T. N. (2013). Predicting relationship satisfaction in distressed and non-distressed couples based on a stratified sample: A matter of conflict, positivity or support? Family Science, 17, 213-237. https://doi.org/10.1080/19424620.2013.830633 
Hilpert, P., Randall, A. K., Sorokowski, P., Atkins, D., Sorokowksa, A., Ahmadi, K., ... Yoo, G. (2016). The associations of dyadic coping and relationship satisfaction vary between and within nations: A 35-nation study. Frontiers in Psychology, 7, 1106. https://doi. org/10.3389/fpsyg.2016.01106

IBM Corp. (2018). IBM SPSS Statistics für Windows (Version 25.0) [Computer software]. Armonk, NY: IBM Corp.

Johnston, C., \& Mash, E. J. (2001). Families of children with attention-deficit/hyperactivity disorder: Review and recommendations for future research. Clinical Child and Family Psychology Review, 4, 183-207.

Keizer, R., \& Schenk, N. (2012). Becoming a parent and relationship satisfaction: A longitudinal dyadic perspective. Journal of Marriage and Family, 74, 759-773. https://doi.org/10.1111/ j.1741-3737.2012.00991.x

Lazarus, R. S., \& Folkman, S. (1984). Stress, appraisal, and coping. New York, NY: Springer.

Little, T. D. (2014). The Oxford handbook of quantitative methods. New York, NY: Oxford University Press.

Lohaus, A., Chodura, S., Möller, C., Symanzik, T., Ehrenberg, D., Job, A.-K., ... Heinrichs, N. (2017). Children's mental health problems and their relation to parental stress in foster mothers and fathers. Child and Adolescent Psychiatry and Mental Health, 11, 43. https://doi.org/10.1186/s13034-017-0180-5

McCoy, K. P., Cummings, E. M., \& Davies, P. T. (2009). Constructive and destructive marital conflict, emotional security and children's prosocial behavior. Journal of Child Psychology and Psychiatry, 50, 270-279. https://doi.org/10.1111/j.1469-7610. 2008.01945.x

Mitnick, D. M., Heyman, R. E., \& Smith Slep, A. M. (2009). Changes in Relationship satisfaction across the transition to parenthood: A meta-analysis. Journal of Family Psychology, 23, 848-852. https://doi.org/10.1037/a0017004

Morgan, J., Robinson, D., \& Aldridge, J. (2002). Parenting stress and externalizing child behavior. Child and Family Social Work, 7, 219-225. https://doi.org/10.1046/j.1365-2206.2002. 00242.x

Muthén, L. K., \& Muthén, B. O. (2017). Mplus user's guide (8th ed.). Los Angeles, CA: Muthén \& Muthén.

Neuschwander, M., In-Albon, T., Adornetto, C., Roth, B., \& Schneider, S. (2013). Interrater-Reliabilität des Diagnostischen Interviews bei psychischen Störungen im Kindes- und Jugendalter (Kinder-DIPS) [Inter-rater reliability of the Diagnostic Interview of Mental Disorders in Childhood and Adolescents (Kinder-DIPS)]. Zeitschrift für Kinder- und Jugendpsychiatrie und Psychotherapie, 41, 319-334. https://doi.org/10.1024/1422-4917/a000247

Obermüller, K. (2012). Beziehungsqualität und dyadisches Coping. Ein Vergleich von Paaren mit einem Kind mit intellektueller Behinderung und einem Kind ohne intellektuelle Behinderung [Relationship quality and dyadic coping. A comparison of couples with a child with an intellectual disability and couples with a child without an intellectual disability]. (Diploma dissertation, Universität Wien, Vienna, Austria). Retrieved from http://othes.univie.ac.at/20168/

Perry, N. B., Donzella, B., Parenteau, A. M., Desjardins, C., \& Gunnar, M. R. (2019). Emotion regulation and cortisol reactivity during a social evaluative stressor: A study of post-institutionalized youth. Developmental Psychobiology, 61, 1-16. https:// doi.org/10.1002/dev.21828

Rubin, D. M., O'Reilly, A. L. R., Luan, X., \& Localio, A. R. (2007). The impact of placement stability on behavioral well-being for children in foster care. Pediatrics, 119, 336-344. https://doi. org/10.1542/peds.2006-1995

Russell, K. E. (2014). The effects of fostering on communication and marital quality in the marital dyadic relationship. Theses and Dissertations, 2292. Retrieved from http://scholarworks. uark.edu/etd/2292/
Satorra, A., \& Bentler, P. M. (2010). Ensuring positiveness of the scaled difference chi-square test statistic. Psychometrika, 57, 243-248. https://doi.org/10.1007/s11336-009-9135-y

Schermerhorn, A. C., Cummings, E. M., De Carlo, C. A., \& Davies, P. T. (2007). Children's influence in the marital relationship. Journal of Family Psychology, 21, 259-269. https://doi.org/ 10.1037/0893-3200.21.2.259

Schneider, S., Suppiger, A., Adornetto, C., \& Unnewehr, S. (2009). Handbuch zum Kinder-DIPS [Manual for the Kinder-DIPS]. In S. Schneider, S. Unnewehr, \& J. Margraf (Eds.), Diagnostisches Interview bei psychischen Störungen im Kindes- und Jugendalter [Diagnostic interview of mental disorders in childhood and adolescents]. Berlin, Germany: Springer.

Teyhan, A., Wijedasa, D., \& Macleod, J. (2018). Adult psychosocial outcomes of men and women who were looked-after or adopted as children: Prospective observational study. BMJ Open, 8, e019095. https://doi.org/10.1136/bmjopen-2017019095

Traa, M. J., De Vries, J., Bodenmann, G., \& Den Oudsten, B. L. (2015). Dyadic coping and relationship functioning in couples coping with cancer: A systematic review. British Journal of Health Psychology, 20, 85-114. https://doi.org/10.1111/bjhp. 12094

Unnewehr, S., Adornetto, C., Suppiger, A., Margraf, J., \& Schneider, S. (Eds.). (2009). Diagnostisches Interview bei psychischen Störungen im Kindes- und Jugendalter (Kinder-DIPS) [Clinical interview for mental disorders in childhood and adolescence] (2nd ed.). Berlin, Germany: Springer.

Vanschoonlandt, F., Vanderfaeillie, J., Van Holen, F., De Maeyer, S., \& Robberechts, M. (2013). Parenting stress and parenting behavior among foster mothers of foster children with externalizing problems. Children \& Youth Services Review, 35, 1742-1750. https://doi.org/10.1016/j.childyouth.2013.07. 012

Vasileva, M., \& Petermann, F. (2018). Attachment, development, and mental health in abused and neglected preschool children in foster care: A meta-analysis. Trauma, Violence, \& Abuse, 19, 443-458. https://doi.org/10.1177/1524838016669503

Zemp, M. (2018). Die elterliche Paarbeziehung in Familien mit Kindern mit ADHS: Wechselwirkungen zwischen Partnerschaftsstörungen und kindlicher Symptomatik [The interparental relationship in families with children with ADHD: Interactions between couple distress and child's symptoms]. Zeitschrift für Kinder- und Jugendpsychiatrie und Psychotherapie, 46, 285-297. https://doi.org/10.1024/1422-4917/a000558

Zemp, M., Bodenmann, G., Backes, S., Sutter-Stickel, D., \& Revenson, T. A. (2016). The importance of parents' dyadic coping for children. Family Relations, 65, 275-286. https://doi. org/ 10.1111/fare.12189

Zemp, M., Bodenmann, G., \& Cummings, E. M. (2016). The significance of interparental conflict for children. Rationale for couplefocused programs in family therapy. European Psychologist, 21, 99108. https://doi.org/10.1027/1016-9040/a000245

Zemp, M., Merrilees, C. E., \& Bodenmann, G. (2014). How much positivity is needed to buffer the impact of parental negativity on children? Family Relations, 63, 602-615. https://doi.org/ 10.1111/fare.12091

Zemp, M., Milek, A., Cummings, E. M., Cina, A., \& Bodenmann, G. (2016). How parenting- and couple-focused programs affect child behavioral problems: A randomized controlled trial. Journal of Child and Family Studies, 25, 798-810. https://doi. org/10.1007/s10826-015-0260-1

Zemp, M., Nussbeck, F. W., Cummings, E. M., \& Bodenmann, G. (2017). The spillover of child-related stress into parents' relationship mediated by couple communication. Family Relations, 66, 317-330. https://doi.org/10.1111/fare.12244 
Zimet, D. M., \& Jacob, T. (2001). Influences of marital conflict on child adjustment: Review of theory and research. Clinical Child and Family Psychology Review, 4, 319-335. https://doi.org/ 10.1023/A:1013595304718

\section{Publication Ethics}

The study was carried out in accordance with the Declaration of Helsinki. Prior to the enrolment of the first family, all procedures and assessments were approved by the Ethics Committee of the German Psychological Society (DGPs) and by the local ethics committees at Bielefeld University, at the University of Braunschweig, and at the University Hospital Aachen. To participate in the study, those who were holding child custody (biological parent[s], foster parent[s]), or legal guardian) were informed about the project and had to give their written informed consent for a family's participation in the project.

\section{Open Data}

The datasets for this manuscript are not publicly available because these are sensitive data and participants did not give their written informed consent for making their data accessible for others. Requests to access the datasets should be directed to Ann-Katrin Job (a-k.job@tu-braunschweig.de).

\section{Funding}

The GROW\&TREAT project was funded by the German Federal Ministry of Education and Research (BMBF; funding code: 01KR1302)

\section{Ann-Katrin Job}

Department of Psychology

Institute of Clinical Psychology, Psychotherapy and Assessment University of Braunschweig

Humboldtstraße 33

38106 Braunschweig

Germany

a-k.job@tu-braunschweig.de 